\title{
Trends in Industry Payments to Physicians for Antihyperglycemic Therapies Between 2014 and 2018
}

J Gen Intern Med 36(8):2492-4

DOI: $10.1007 /$ s11606-020-06215-0

(C) Society of General Internal Medicine 2020

\section{INTRODUCTION}

One in ten Americans have diabetes, and a total of \$327 billion was spent on diabetes care in the USA in $2017 .{ }^{1}$ Moreover, a recent study showed that the spending on all antihyperglycemic therapies for Medicare beneficiaries increased $144 \%$ from 2012 to $2017 .^{2}$ Given the size and competitiveness of the market of antihyperglycemic therapies, pharmaceutical companies market directly to physicians to increase their market share. The financial conflict of interest is concerning given its potential impact on physicians' prescription behavior ${ }^{3}$ and clinical practice guidelines. ${ }^{4}$ However, little is known about the distribution of industry payments to physicians for antihyperglycemic therapies, and more importantly, how it has changed in recent years due to the introduction of newer classes of diabetic medications to the market. To address this knowledge gap, we examined trends in industry payments to physicians for antihyperglycemic therapies from 2014 to 2018.

\section{METHODS}

We analyzed the Centers for Medicare and Medicaid Services Open Payments database in 2014-2018. We extracted the non-research payments data related to antihyperglycemic therapies (defined by the American Diabetes Association $[\mathrm{ADA}]^{5}$ ) in each year using the string variable of marketed drugs in the Open Payments data. When multiple (up to five) drugs were reported in a single payment, we divided the amount of the payment equally by the number of reported drugs. The total amount of payments was adjusted for inflation and presented in 2018 US dollars. All analyses were performed using Stata, version 15. The study was exempted by the University of California, Los Angeles institutional review board.

Received April 27, 2020

Accepted September 3, 2020

Published online September 18, 2020

\section{RESULTS}

In 2018, 1,269,110 general payments for antihyperglycemic therapies worth $\$ 88.8$ million were made to 85,421 US physicians with an average payment value of $\$ 1039$ (maximum, $\$ 1,472,413)$. Speaking fees or honoraria constituted the largest proportion of payments followed by food and beverages (Table 1). Two new classes (sodium-glucose cotransporter-2 inhibitors [SGLT2i]; glucagon-like peptide-1 receptor agonists [GLP-1RA]) comprised $92 \%$ of payments for all noninsulin antihyperglycemic therapies in 2018 (Fig. 1). The total amount of industry payments for SGLT2i increased from 2014 to 2017. However, the payments for GLP-1RA decreased from 2014 to 2017, and the payments for long-acting insulin also decreased from 2016 to 2018 after almost \$20 million increase from 2014 to 2016. Instead, the payments for combination drugs of GLP-1RA and long-acting insulin increased since 2016. Marketing for dipeptidyl peptidase-4 inhibitors and short-acting insulin has decreased since 2014. We did not observe clear trends based on the monthly retail costs for each antihyperglycemic therapy.

\section{DISCUSSION}

To the best of our knowledge, this is the first study investigating the national trends in industry payments related to diabetes care. Our findings suggest that the industry may be promoting two newer classes of antihyperglycemic therapies (SGLT2i and GLP-1RA). SGLT2i and GLP-1RA have been largely prescribed in the US since their approvals by the Food and Drug Administration (FDA) in 2013 and 2005, respectively. Since then, several trials have proved their cardiovascular benefits, ${ }^{6,7}$ and therefore, the ADA guideline recommends these drugs as the first choice for second-line therapy for patients with atherosclerotic cardiovascular disease, heart failure, or chronic kidney disease. ${ }^{5}$

Although we observed the decline in insulin-related payments in 2018, there is still a large amount of industry payments, particularly for long-acting insulins including a biosimilar, highly concentrated insulin, and ultra-long-acting insulin, which were approved by the FDA in 2015-2016. Moreover, payments for a combination drug of insulin and GLP-1RA increased after its approval in 2016. Given the recent concern about the negative impacts of the rising cost 
Table 1 Characteristics of Industry Payments to Physicians for All Antihyperglycemic Therapies 2014-2018

\begin{tabular}{llllll}
\hline \hline Nature of payments & $\mathbf{2 0 1 4}$ & $\mathbf{2 0 1 5}$ & $\mathbf{2 0 1 6}$ & $\mathbf{2 0 1 7}$ & $\mathbf{2 0 1 8}$ \\
\hline Speaking fees or honoraria & $\$ 51,792,450$ & $\$ 52,704,203$ & $\$ 49,100,467$ & $\$ 61,287,171$ \\
Food and beverages & $\$ 28,330,055$ & $\$ 27,366,857$ & $\$ 24,736,042$ & $\$ 25,193,413$ & $\$ 50,282,439$ \\
Consulting fees & $\$ 8,379,827$ & $\$ 7,261,313$ & $\$ 7,123,744$ & $\$ 9,101,453$ \\
Travel and lodging & $\$ 6,981,332$ & $\$ 6,229,000$ & $\$ 6,927,994$ & $\$ 7,913,430$ & $\$ 8,109,603$ \\
Royalty $_{\text {or License }}{ }^{a}$ & $\$ 4,874,288$ & $\$ 7,063,219$ & $\$ 6,708,734$ & $\$ 5,907,831$ \\
Others $_{\text {Total }}^{\$ 859,037}$ & $\$ 388,687$ & $\$ 163,332$ & $\$ 137,545$ \\
\hline
\end{tabular}

${ }^{a}$ Royalty or license includes payments based on sales of products that use a physician's intellectual property (e.g., a certain amount of industry payment received by a physician who worked with the industry to invent a new product). Because this type of industry payments was rare and expensive, the value of industry payments in this category was unstable across the years

${ }^{b}$ Others include education, gift, and facility fees
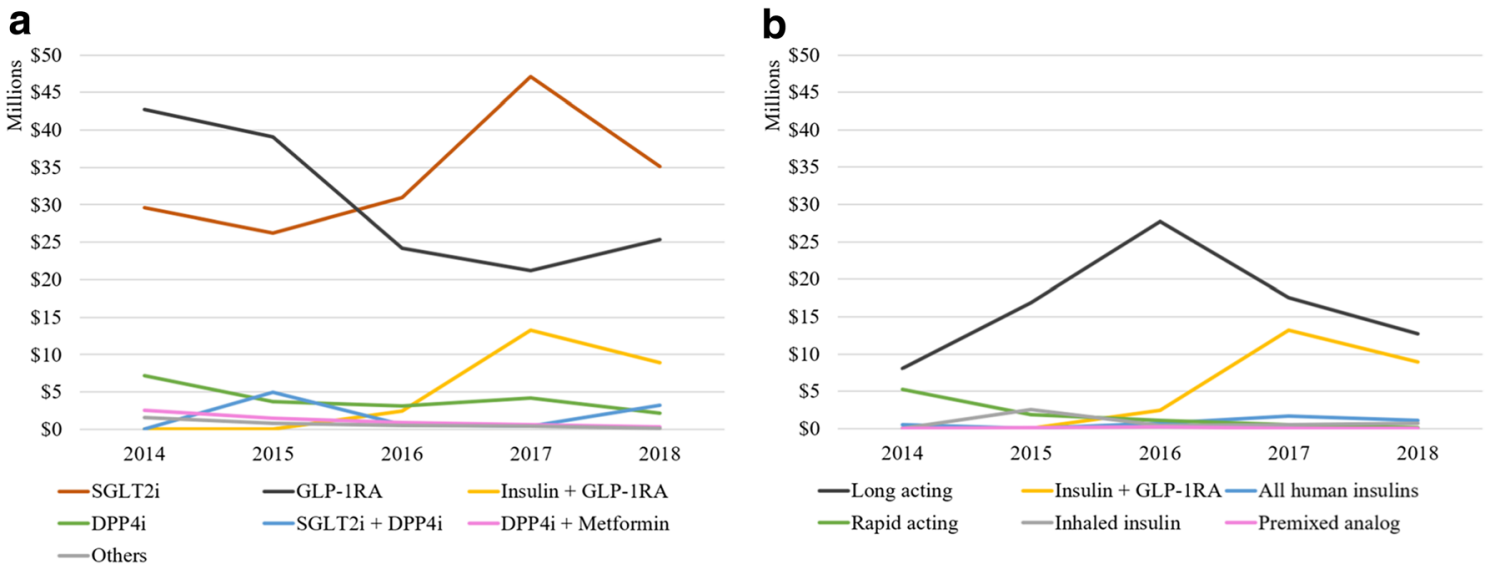

Figure 1 Trends in industry payments to physicians for antihyperglycemic therapies 2014-2018. a Non-insulin antihyperglycemic therapies. b Insulin classes. SGT2i, sodium-glucose cotransporter 2 inhibitors; GLP-1RA, glucagon-like peptide-1 receptor agonists; DPP4i, dipeptidyl peptidase-4 inhibitors.

Others include metformin, thiazolidine, sulfonylurea, alpha-glucosidase inhibitor, amylin, and combination drugs (DPP4i + thiazolidine, SGLT2i + metformin, metformin + sulfonylurea, thiazolidine + sulfonylurea, metformin + thiazolidine, DPP4i + simvastatin).

of insulin on adherence and accessibility of this medication for patients with diabetes, ${ }^{8}$ future research is warranted to identify how industry marketing of these medications influence physicians' prescription practices.

Limitations of this study include our inability to consider physician-level characteristics (e.g., specialties, years in practice, affiliation), industry profits, and possible measurement error in the Open Payments database.

In conclusion, using the national database on industry payments to physicians, our descriptive study showed that industry marketing to physicians for antihyperglycemic therapies peaked in 2017, and newer therapies have constituted the large proportion of industry payments to physicians. Whether the physician-industry financial relationship related to these antihyperglycemic therapies affects physicians' clinical decision-making, development of clinical guidelines, patients' health outcomes, and US healthcare costs should be further investigated.

Kosuke Inoue, $M D^{1}$

O. Kenrik Duru, $M D, M S^{2}$

Carol M. Mangione, $\mathrm{MD}, \mathrm{MSPH}^{2,3}$

Yusuke Tsugawa, $\mathrm{MD}, \mathrm{Ph} \mathrm{D}^{2,3}$
${ }^{1}$ Department of Epidemiology, UCLA Fielding School of Public Health,

Los Angeles, CA 90095, USA

${ }^{2}$ Medicine \& Health Policy and Management, Division of General Internal Medicine and Health Services Research, David Geffen School of Medicine at UCLA, Los Angeles, CA 90024, USA

${ }^{3}$ Department of Health Policy and Management, UCLA Fielding School of Public Health,

Los Angeles, CA, USA

Corresponding Author: Kosuke Inoue, MD; Department of Epidemiology, UCLA Fielding School of Public Health, Los Angeles, CA 90095, USA (e-mail: koinoue@ucla.edu).

Author Contributions All authors had full access to all of the data in the study and took responsibility for the integrity of the data and the accuracy of the data analysis.

Concept and design: Inoue and Tsugawa

Acquisition, analysis, or interpretation of data: Inoue and Tsugawa Drafting of the manuscript: All authors

Critical revision of the manuscript for important intellectual content: All authors.

Funding KI was supported by the Burroughs Wellcome Fund Interschool Training Program in Chronic Diseases (BWF-CHIP) and Honjo International Scholarship Foundation. CMM and OKD are supported by CDC cooperative agreement U18DP006128-04 and NIH/NIDDK 
grant R18DK105464-04. CMM is also supported by the Barbara A. Levey and Gerald S. Levey Endowed Chair in Medicine.

\section{Compliance with ethical standards:}

The study was exempted by the University of California, Los Angeles institutional review board.

Conflict of Interest: The authors declare that they do not have a conflict of interest.

Disclaimer: The funders had no role in the design and conduct of the study; collection, management, analysis, and interpretation of the data; preparation, review, or approval of the manuscript; and decision to submit the manuscript for publication.

\section{REFERENCES}

1. CDC. National Diabetes Statistics Report, 2020. Centers for Disease Control and Prevention. Published February 11, 2020. Accessed June 13, 2020. https://www.cdc.gov/diabetes/library/features/diabetes-stat-report.html

2. Sumarsono A, Everett BM, McGuire DK, et al. Trends in Aggregate Use and Associated Expenditures of Antihyperglycemic Therapies Among US Medicare Beneficiaries Between 2012 and 2017. JAMA Intern Med. 2020;180(1):141-144. doi:https://doi.org/10.1001/jamainternmed.2019. 3884

3. Steinbrook R. Industry Payments and Physician Prescribing. JAMA Intern Med. 2019;179(10):1428-1429. doi:https://doi.org/10.1001/ jamainternmed.2019.1081
4. Norris SL, Holmer HK, Ogden LA, Burda BU, Fu R. Conflicts of Interest among Authors of Clinical Practice Guidelines for Glycemic Control in Type 2 Diabetes Mellitus. PLoS One. 2013;8(10). doi:https://doi.org/10.1371/ journal.pone.0075284

5. Association AD. 9. Pharmacologic Approaches to Glycemic Treatment: Standards of Medical Care in Diabetes-2019. Diabetes Care. 2019;42(Supplement 1):S90-S102. doi:https://doi.org/10.2337/dc19S009

6. Zelniker TA, Wiviott SD, Raz I, et al. SGLT2 inhibitors for primary and secondary prevention of cardiovascular and renal outcomes in type 2 diabetes: a systematic review and meta-analysis of cardiovascular outcome trials. The Lancet. 2019;393(10166):31-39. doi:https://doi.org/10.1016/ S0140-6736(18)32590-X

7. Kristensen SL, Rørth R, Jhund PS, et al. Cardiovascular, mortality, and kidney outcomes with GLP-1 receptor agonists in patients with type 2 diabetes: a systematic review and meta-analysis of cardiovascular outcome trials. Lancet Diabetes Endocrinol 2019;7(10):776-785. doi:https://doi. org/10.1016/S2213-8587(19)30249-9

8. Fralick M, Kesselheim AS. The U.S. Insulin Crisis - Rationing a Lifesaving Medication Discovered in the 1920s. New England J Med 2019;381(19): 1793-1795. doi:https://doi.org/10.1056/NEJMp 1909402

Publisher's Note Springer Nature remains neutral with regard to jurisdictional claims in published maps and institutional affiliations.

jurisdictional claims in püblished maps and institutional affiliations. 